\title{
Erythrocyte fatty acid profiles can predict acute non-fatal myocardial infarction
}

\author{
Yongsoon Park ${ }^{1}$, Jeehyun Lim $^{1}$, Jaeung Lee ${ }^{2}$ and Soon-gil Kim ${ }^{2}$ \\ ${ }^{1}$ Department of Food and Nutrition, Hanyang University, Seoul, South Korea \\ ${ }^{2}$ Cardiology Division, Department of Internal Medicine, Hanyang University Kuri Hospital, Kuri, South Korea \\ (Received 27 January 2009 - Revised 11 April 2009 - Accepted 24 April 2009 - First published online 9 June 2009)
}

The risk of CHD has been linked to $n-3$ and trans-fatty acids. The purpose of the present study was to evaluate the hypothesis that lower $n-3$ fatty acids and higher trans-fatty acids in erythrocytes are associated with an increased risk of acute non-fatal myocardial infarction (MI), and that fatty acid profiles can discriminate MI cases from controls. Fifty cases with acute non-fatal MI and fifty age- and sex-matched controls without MI were recruited. The Omega-3 Index (the sum of EPA and DHA in erythrocytes) was significantly lower in cases than controls (9.57 (SEM 0.28) v. 11.81 (SEM 0.35$) \% ; P<0.001$ ), while total trans-fatty acids were significantly higher (1.01 (SEM 0.04) v. 0.56 (SEM 0.03) $\% ; P<0.001)$. The Omega-3 Index was associated with decreased risk of MI (OR 0.08 (95\% CI 0.02, 0.38); $P=0.001)$, while total trans-fatty acids were associated with an increased risk of MI (OR 72.67 (95\% CI 6.68, 790.74); $P<0.001)$. The area under the receiver operating characteristic curve of fatty acid profiles was larger than that for traditional risk factors, suggesting that fatty acid profiles make a higher contribution to the discrimination of MI cases from controls compared with modified Framingham risk factors. In conclusion, a higher Omega-3 Index and lower trans-fatty acids in erythrocytes are associated with a decreased risk of MI. Furthermore, fatty acid profiles improve discrimination of acute non-fatal MI compared with established risk factors.

Lipidome: Myocardial infarction: $n$-3 Fatty acids: Trans-fatty acids: Risk factors

The presence of long-chain $n-3$ fatty acids such as EPA $(20: 5 n-3)$ and DHA $(22: 6 n-3)$ in the diet is associated with a lower risk of $\mathrm{CHD}^{(1)}$. The Diet and Reinfarction Trial $(\text { DART })^{(2)}$, Gruppo Italiano per lo Studio della Sopravvivenza nell'Infarto Miocardico (GISSI)-Prevenzione (Italian group for the study of the survival of myocardial infarction) ${ }^{(3)}$ and the Japan EPA Lipid Intervention Study (JELIS) ${ }^{(4)}$ have shown that oily fish, EPA and DHA, and EPA alone significantly reduce cardiac death, but do not significantly affect the risk of non-fatal CHD. The association between EPA and DHA and the risk of non-fatal myocardial infarction (MI) is, however, unclear. Higher fish intake is significantly associated with reduced risk for non-fatal $\mathrm{MI}^{(5)}$, but the associations between EPA and DHA levels in erythrocytes and reduced risk for non-fatal MI were not significant in the Nurses' Health cohort study ${ }^{(6)}$. Two cohort studies of men also found non-significant relationships between fish intake and the risk of non-fatal $\mathrm{MI}^{(7,8)}$. Therefore, despite intensive investigations into the association between $n-3$ fatty acids and non-fatal MI, no clear pattern has emerged.

The Framingham risk score is the most widely used system for CHD risk prediction ${ }^{(9,10)}$, but additional markers are required. The amount of long-chain $n-3$ fatty acids in erythrocyte membranes, as assessed by the Omega- 3 Index (sum of EPA and DHA in erythrocytes), was shown to be a significant and independent discriminator of $\mathrm{CHD}^{(11)}$. Other studies have shown that fatty acids, particularly trans-fatty acids ${ }^{(12)}$ or $n-6$ fatty acids ${ }^{(13)}$, are positively associated with MI risk. However, the relationship between the fatty acid profile and the risk of non-fatal MI has not been investigated, even though the fatty acid profile or 'lipidome' may be key to identifying MI diet-related risk because fatty acids are associated with systemic inflammation, endothelial dysfunction and lipoproteins, all of which have previously been demonstrated to be independent risk factors for $\mathrm{CHD}^{(14-16)}$.

To help elucidate the association between $n-3$ fatty acids and acute non-fatal MI, we determined if the Omega-3 Index is lower in patients with acute non-fatal MI compared with controls. Furthermore, we examined whether fatty acid profiles can independently predict non-fatal MI cases and add to the predictive power of the Framingham risk score.

\section{Subjects and methods}

Subjects

Subjects were recruited consecutively from acute non-fatal MI patients admitted to Hanyang University Kuri Hospital between November 2006 and May 2008. Cases consisted of patients diagnosed with their first case of ST-segment

Abbreviations: ALA, $\alpha$-linolenic acid; MI, myocardial infarction; Omega-3 Index, sum of EPA and DHA in erythrocytes.

* Corresponding author: Professor Yongsoon Park, fax +82 022292 1226, email yongsoon@ hanyang.ac.kr 
elevated MI. Control subjects were age-and sex-matched to the case subjects; patients were excluded if they had a history of CHD, cancer, hyperlipidaemia or diabetes. The present study was conducted according to the guidelines laid down in the Declaration of Helsinki and all procedures involving human subjects and patients were approved by the institutional review board of Hanyang University Kuri Hospital, and informed, written consent was obtained from all participants. Anthropometric data, medical history and socio-economic status were obtained from both medical chart reviews and interviews.

\section{Laboratory measurements}

Fasting blood samples were collected in EDTA and serum separator (SST) blood tubes during the day of admission, centrifuged and then divided into samples for storage at $-80^{\circ} \mathrm{C}$. Erythrocytes were directly methylated by adding boron trifluoride methanol-benzene (B1252; Sigma-Aldrich, St Louis, MO, USA) and heated for $10 \mathrm{~min}$ at $100^{\circ} \mathrm{C}$. Fatty acids methyl esters were analysed by GC (Shimadzu 2010AF; Shimadzu Scientific Instrument, Kyoto, Japan) with a $100 \mathrm{~m}$ SP2560 capillary column (Supelco, Bellefonte, PA, USA). Fatty acids were identified by comparison with known standards (GLC-727; Nu-Check Prep, Elysian, MN, USA). In the standard, the trans-18:1 peak was a mixture of trans-18:1n-12, trans-18:1n-9 and trans-18:1n-7, while the trans-18:2n-6 peak contained trans,trans-18:2n-6. The Omega-3 Index was calculated as the sum of erythrocyte concentrations of EPA and DHA and expressed as percentage of total fatty acids in erythrocyte membrane ${ }^{(11)}$. The quality-control sample comprised pooled erythrocytes, and the $\mathrm{CV}$ was $5.6 \%$.

Plasma leptin (human leptin; Invitrogen Inc., Carlsbad, CA, USA), adiponectin (Human Adiponectin/Acrp30 Immunoassay; R\&D Systems Inc., Minneapolis, MN, USA) and insulin levels (human insulin; Invitrogen Inc.) were measured by ELISA. Serum lipid profiles (TBA-30FR; Toshiba, Tokyo, Japan), blood chemicals (Coulter LH 750 analyser; Beckman Coulter Inc., Fullerton, CA, USA), liver function (Variant; Bio-RAD, Hercules, CA, USA) and high-sensitivity C-reactive protein concentrations (Wr-CRP Advia 1650; Bayer, Berkeley, CA, USA) were measured with autoanalysers.

\section{Statistical analysis}

Continuous variables were expressed as mean values with their standard errors to compare cases and controls using independent $t$ tests. Proportions of nominal variables were compared using the $\chi^{2}$ test and correlation between variables was tested by partial correlation analysis after adjusting for age and sex. Fatty acids were categorised into tertiles based on control values. Binary logistic regression was adjusted for matching variables and used to find an association between baseline concentration and dependent factors. Analyses of fatty acids such as EPA, $\alpha$-linolenic acid (ALA; 18:3n-3), trans-18:1n-9 (trans-oleic acid) and 20:4n-6 (arachidonic acid) were developed using stepwise selection to reduce the number of fatty acids to a subset of the ones with greatest impact. The calculation of the Framingham risk scores includes age, sex, smoking status, total cholesterol, HDLcholesterol, and a history of diabetes and hypertension ${ }^{(17)}$.
A combination model was developed that included the fatty acids selected in multivariable logistic regression and the Framingham risk score used in the multivariable logistic regression. The area under the receiver operating characteristic curve was determined to compare the explanatory power of fatty acids, Framingham risk score, and a combination of fatty acids and Framingham risk score. A $P$ value of $<0.05$ was considered statistically significant. Statistical analysis was performed using SPSS version 12.0 (SPSS Inc., Chicago, IL, USA).

\section{Results}

\section{Subject characteristics}

The characteristics of subjects are shown in Table 1. There was a greater incidence of a history of diabetes and a family history of CHD in the cases compared with the controls. Although not significant, BMI was higher in the cases than the controls. In addition, sex, age, education level, exercise, smoking, drinking, period of smoking and drinking, and history of hypertension did not differ significantly between the cases and the controls.

\section{Metabolic parameters}

Leucocyte counts, the aspartic acid transaminase:alanine transaminase ratio, and levels of aspartic acid transaminase, total cholesterol, LDL-cholesterol, high-sensitivity C-reactive

Table 1. Characteristics of the study subjects

(Mean values with their standard errors or numbers of subjects)

\begin{tabular}{|c|c|c|c|c|c|}
\hline & \multicolumn{2}{|c|}{ Cases (n 50) } & \multicolumn{2}{|c|}{$\begin{array}{l}\text { Controls } \\
(n 50)\end{array}$} & \multirow[b]{2}{*}{$P$} \\
\hline & Mean & SEM & Mean & SEM & \\
\hline $\operatorname{Sex}(n)$ & & & & & 0.509 \\
\hline Male & \multicolumn{2}{|l|}{37} & \multicolumn{2}{|c|}{34} & \\
\hline Female & \multicolumn{2}{|l|}{13} & \multicolumn{2}{|c|}{16} & \\
\hline Age (years) & $58 \cdot 1$ & $1 \cdot 7$ & $54 \cdot 6$ & $2 \cdot 1$ & $0.202 \dagger$ \\
\hline BMI $\left(\mathrm{kg} / \mathrm{m}^{2}\right)$ & $24 \cdot 6$ & 0.4 & $23 \cdot 2$ & 0.7 & $0.081 \dagger$ \\
\hline Exercise $(n)$ & & & & & 0.316 \\
\hline No & \multicolumn{2}{|l|}{21} & \multicolumn{2}{|c|}{26} & \\
\hline Yes & \multicolumn{2}{|l|}{29} & \multicolumn{2}{|c|}{24} & \\
\hline Smoking $(n)$ & & & & & 0.836 \\
\hline No & \multicolumn{2}{|l|}{18} & \multicolumn{2}{|c|}{19} & \\
\hline Yes & \multicolumn{2}{|l|}{32} & \multicolumn{2}{|c|}{31} & \\
\hline Period of smoking (years) & $32 \cdot 1$ & 1.5 & $26 \cdot 2$ & $2 \cdot 8$ & $0.064 \dagger$ \\
\hline Alcohol drinking $(n)$ & & & & & 0.410 \\
\hline No & \multicolumn{2}{|l|}{17} & \multicolumn{2}{|c|}{21} & \\
\hline Yes & \multicolumn{2}{|l|}{33} & \multicolumn{2}{|c|}{29} & \\
\hline $\begin{array}{l}\text { Period of alcohol drinking } \\
\text { (years) }\end{array}$ & $28 \cdot 7$ & $3 \cdot 6$ & $26 \cdot 5$ & 2.9 & $0.925 \dagger$ \\
\hline History of hypertension $(n)$ & & & & & 0.829 \\
\hline No & \multicolumn{2}{|l|}{35} & \multicolumn{2}{|c|}{34} & \\
\hline Yes & \multicolumn{2}{|l|}{15} & \multicolumn{2}{|c|}{16} & \\
\hline History of diabetes $(n)$ & & & & & 0.027 \\
\hline No & \multicolumn{2}{|l|}{35} & \multicolumn{2}{|c|}{44} & \\
\hline Yes & \multicolumn{2}{|c|}{$15^{\star}$} & \multicolumn{2}{|c|}{6} & \\
\hline Family history of CHD $(n)$ & & & & & 0.027 \\
\hline No & \multicolumn{2}{|l|}{43} & \multicolumn{2}{|c|}{49} & \\
\hline Yes & \multicolumn{2}{|l|}{$7^{*}$} & \multicolumn{2}{|c|}{1} & \\
\hline
\end{tabular}

${ }^{\star} P<0.05\left(\chi^{2}\right.$ test $)$

$\dagger$ By independent $t$ test. 
protein and leptin were significantly higher in the cases than the controls $(P<0.05)$, while adiponectin levels were significantly lower in the cases than the controls $(P=0.037$; Table 2). Erythrocyte and platelet counts, $\mathrm{Hb}$, packed cell volume, mean platelet volume, $\mathrm{Hb}-\mathrm{A} 1 \mathrm{c}$, albumin, $\mathrm{Ca}$, fasting glucose, blood urea $\mathrm{N}$, alanine transaminase, TAG and HDL-cholesterol levels were not significantly different between groups.

\section{Erythrocyte fatty acid composition}

The Omega-3 Index was significantly lower in the cases than the controls $(9.57 v .11 .81 \% ; P<0.001)$, while total trans-fatty acids were significantly higher (1.01 (SEM 0.04) v. 0.56 (SEM $0.03) \% ; P<0.001)$. EPA and ALA levels were also significantly lower in the cases than the controls, but total trans-fatty acids, trans-18:1, arachidonic acid, 16:0 and $22: 4 n-6$ were significantly higher in the cases than the controls. Multivariable-adjusted regression analysis showed that the Omega-3 Index, EPA and ALA were negatively $(P<0 \cdot 05)$ associated with the risk of acute non-fatal MI after adjusting for age, sex, history of diabetes, family history of CHD, smoking status, hypertension status, and levels of glucose, total cholesterol and HDL-cholesterol (Table 3). However, total trans-fatty acids, trans-18:1 and arachidonic acid were positively associated with the risk of acute nonfatal MI after adjusting for all confounding variables. The Omega-3 Index, and EPA and ALA levels were negatively related to the concentration of high-sensitivity C-reactive protein, but total trans-fatty acids and trans-oleic acids were positively related to the concentration of high-sensitivity C-reactive protein concentration (Table 4). Trans-oleic acid was significantly related to the levels of leptin and adiponectin, respectively, and trans-linoleic acid was positively related to the concentration of TAG. The Omega-3 Index, and ALA and EPA levels were negatively related to the concentration of glucose, while only EPA was negatively related to the total cholesterol level. Linoleic acid was negatively related to TAG, but was positively associated with LDL- and HDLcholesterol concentrations.

The ability of risk scores, such as the traditional risk score and the fatty acids risk score including EPA, ALA, trans-oleic acid and arachidonic acid, to discriminate cases from controls was compared, both alone and in combination (Fig. 1). The area under the receiver operating characteristic curve of the fatty acid risk score alone (0.97) was better than that of the traditional risk score $(0.68)$ as well as the combination of the two risk scores $(0 \cdot 95)$.

\section{Discussion}

In the present study, the fatty acid composition of erythrocytes was associated with the risk of occurrence of acute non-fatal MI. The risk of acute non-fatal MI was significantly reduced by a higher Omega-3 Index, $n-3$ fatty acids, EPA and ALA after adjusting for age, sex, history of diabetes, family history of CHD, smoking status, hypertension status, and levels of glucose, total cholesterol and HDL-cholesterol. In contrast, higher levels of total trans-fatty acids, trans-18:1 and $20: 4 n-6$ were associated with an increased risk of acute non-fatal MI. To the best of our knowledge, the present study is the first to demonstrate that the fatty acid profile (lipidome) of erythrocytes can allow discrimination between acute non-fatal MI cases and controls. Furthermore, the fatty

Table 2. Metabolic parameters in cases and controls (Mean values with their standard errors)

\begin{tabular}{|c|c|c|c|c|c|}
\hline & \multicolumn{2}{|c|}{ Cases $(n 50)$} & \multicolumn{2}{|c|}{ Controls ( $n$ 50) } & \multirow[b]{2}{*}{$P$} \\
\hline & Mean & SEM & Mean & SEM & \\
\hline Leucocytes $\left(\times 10^{6} / \mathrm{mm}^{3}\right)$ & $11 \cdot 45^{\star \star \star}$ & 0.56 & $7 \cdot 76$ & 0.60 & $<0.001$ \\
\hline Erythrocytes $\left(\times 10^{6} / \mathrm{mm}^{3}\right)$ & $4 \cdot 31$ & $0 \cdot 10$ & $4 \cdot 18$ & 0.09 & 0.334 \\
\hline $\mathrm{Hb}(\mathrm{g} / \mathrm{l})$ & $137 \cdot 9$ & $3 \cdot 0$ & $133 \cdot 2$ & $3 \cdot 0$ & $0 \cdot 276$ \\
\hline Packed cell volume (\%) & $39 \cdot 33$ & $1 \cdot 12$ & 38.54 & 0.79 & 0.566 \\
\hline Platelets $\left(\times 10^{6} / \mathrm{ml}\right)$ & $241 \cdot 80$ & 8.89 & $249 \cdot 90$ & $12 \cdot 38$ & 0.596 \\
\hline Procalcitonin (\%) & 0.19 & 0.01 & 0.20 & 0.01 & 0.435 \\
\hline Mean platelet volume (fl) & $7 \cdot 86$ & 0.09 & $7 \cdot 90$ & 0.12 & 0.424 \\
\hline $\mathrm{Hb}-\mathrm{A} 1 \mathrm{c}(\mathrm{g} / \mathrm{l})$ & $65 \cdot 2$ & 2.5 & 61.4 & 4.4 & 0.429 \\
\hline Albumin (g/l) & $38 \cdot 5$ & 0.5 & $38 \cdot 3$ & 0.9 & 0.886 \\
\hline $\mathrm{Ca}(\mathrm{mg} / \mathrm{l})$ & $83 \cdot 8$ & 0.7 & $85 \cdot 8$ & 0.9 & 0.077 \\
\hline Glucose (mg/l) & $1160 \cdot 9$ & $72 \cdot 5$ & 1015.9 & $44 \cdot 7$ & 0.093 \\
\hline Blood urea N (mg/l) & $157 \cdot 6$ & $12 \cdot 7$ & $151 \cdot 2$ & $9 \cdot 5$ & 0.689 \\
\hline AST (IU/I) & $190 \cdot 74^{\star \star \star}$ & 23.40 & $57 \cdot 40$ & $21 \cdot 78$ & $<0.001$ \\
\hline ALT (IU/I) & $68 \cdot 69$ & $12 \cdot 03$ & 73.54 & 32.54 & 0.890 \\
\hline AST:ALT ratio & $2.93^{\star \star \star}$ & 0.22 & $1 \cdot 17$ & 0.08 & $<0.001$ \\
\hline TAG (mg/l) & $1659 \cdot 6$ & $377 \cdot 3$ & $1121 \cdot 6$ & $81 \cdot 3$ & 0.169 \\
\hline Total cholesterol (mg/l) & $1702 \cdot 5^{\star}$ & $54 \cdot 5$ & 1505.9 & $64 \cdot 7$ & 0.022 \\
\hline HDL-cholesterol (mg/l) & 413.9 & $11 \cdot 7$ & 391.6 & $22 \cdot 6$ & 0.385 \\
\hline LDL-cholesterol (mg/l) & $963 \cdot 3^{*}$ & $48 \cdot 6$ & $797 \cdot 7$ & $53 \cdot 4$ & 0.024 \\
\hline High sensitive C-reactive protein (mg/l) & $24 \cdot 6^{\star \star \star}$ & $3 \cdot 1$ & $9 \cdot 6$ & 3.9 & 0.004 \\
\hline Adiponectin (mg/l) & $5 \cdot 9^{\star}$ & 0.5 & $8 \cdot 2$ & 0.9 & 0.037 \\
\hline Leptin $(\mu \mathrm{g} / \mathrm{l})$ & $14 \cdot 7^{\star}$ & 0.2 & $7 \cdot 8$ & 0.8 & 0.029 \\
\hline Insulin (mg/l) & $1 \cdot 1$ & 0.2 & $1 \cdot 0$ & 0.1 & 0.681 \\
\hline
\end{tabular}

AST, aspartic acid transaminase; ALT, alanine transaminase.

Mean value was significantly different from that of the control group: ${ }^{*} P<0.05,{ }^{\star \star \star} P<0.001$. 
Table 3. Association of fatty acid composition of erythrocytes with the risk of acute non-fatal myocardial infarction by multivariable regression analysis $\dagger$

(Odds ratios and $95 \%$ confidence intervals)

\begin{tabular}{|c|c|c|c|c|}
\hline & \multicolumn{3}{|c|}{ Tertile of erythrocyte fatty acid concentration (\%) } & \multirow[b]{2}{*}{$P$ trend } \\
\hline & 1 & 2 & 3 & \\
\hline \multicolumn{5}{|l|}{$14: 0$} \\
\hline No. of cases & 19 & 20 & 11 & \\
\hline No. of controls & 16 & 17 & 17 & \\
\hline Blood fatty acids cut-off & $\leq 0.26$ & $0.26<$ to $\leq 0.37$ & $>0.37$ & \\
\hline OR & 1.00 & 0.65 & 0.55 & 0.342 \\
\hline $95 \% \mathrm{Cl}$ & & $0.21,2.03$ & $0.17,1.79$ & \\
\hline \multicolumn{5}{|l|}{$16: 0$} \\
\hline No. of cases & 11 & 8 & 31 & \\
\hline No. of controls & 16 & 17 & 17 & \\
\hline Blood fatty acids cut-off & $\leq 21.60$ & $21.60<$ to $\leq 22.57$ & $>22.57$ & \\
\hline OR & 1.00 & 0.59 & $2 \cdot 21$ & 0.205 \\
\hline $95 \% \mathrm{Cl}$ & & $0 \cdot 16,2 \cdot 10$ & $0.71,6.88$ & \\
\hline \multicolumn{5}{|l|}{$16: 1 n-7$} \\
\hline No. of cases & 3 & 24 & 23 & \\
\hline No. of controls & 16 & 17 & 17 & \\
\hline Blood fatty acids cut-off & $\leq 0.29$ & $0.29<$ to $\leq 0.55$ & $>0.55$ & \\
\hline OR & 1.00 & $11.77^{\star \star}$ & $9 \cdot 00^{*}$ & 0.128 \\
\hline $95 \% \mathrm{Cl}$ & & $2 \cdot 22,62 \cdot 44$ & $1.60,50 \cdot 50$ & \\
\hline \multicolumn{5}{|l|}{$18: 0$} \\
\hline No. of cases & 21 & 19 & 10 & \\
\hline No. of controls & 16 & 17 & 17 & \\
\hline Blood fatty acids cut-off & $\leq 16.34$ & $16.34<$ to $\leq 18.05$ & $>18.05$ & \\
\hline OR & 1.00 & 0.85 & 0.43 & 0.158 \\
\hline $95 \% \mathrm{Cl}$ & & $0.27,2.67$ & $0.13,1.38$ & \\
\hline \multicolumn{5}{|l|}{ trans-18:1n-9 } \\
\hline No. of cases & 1 & 1 & 48 & \\
\hline No. of controls & 17 & 16 & 17 & \\
\hline Blood fatty acids cut-off & $\leq 0.22$ & $0.22<$ to $\leq 0.35$ & $>0.35$ & $<0.001$ \\
\hline OR & 1.00 & 1.24 & $50 \cdot 53^{\star *}$ & \\
\hline $95 \% \mathrm{Cl}$ & & $0.06,27.58$ & $5 \cdot 29,482 \cdot 66$ & \\
\hline \multicolumn{5}{|l|}{$18: 1 n-9$} \\
\hline No. of cases & 9 & 15 & 26 & \\
\hline No. of controls & 16 & 17 & 17 & \\
\hline Blood fatty acids cut-off & $\leq 12.90$ & $12.90<$ to $\leq 14.32$ & $>14.32$ & \\
\hline OR & 1.00 & 1.60 & 2.46 & 0.138 \\
\hline $95 \% \mathrm{Cl}$ & & $0.43,5.99$ & $0 \cdot 74,8 \cdot 14$ & \\
\hline \multicolumn{5}{|l|}{ trans-18:2n-6 } \\
\hline No. of cases & 7 & 26 & 17 & \\
\hline No. of controls & 16 & 17 & 17 & \\
\hline Blood fatty acids cut-off & $\leq 0.19$ & $0.19<$ to $\leq 0.29$ & $>0.29$ & \\
\hline OR & 1.00 & $4.82^{*}$ & 3.84 & 0.175 \\
\hline $95 \% \mathrm{Cl}$ & & $1.33,17.39$ & $0.96,15 \cdot 37$ & \\
\hline \multicolumn{5}{|l|}{$18: 2 n-6$} \\
\hline No. of cases & 9 & 27 & 14 & \\
\hline No. of controls & 16 & 17 & 17 & \\
\hline Blood fatty acids cut-off & $\leq 9.08$ & $9.08<$ to $\leq 11.09$ & $>11.09$ & \\
\hline OR & 1.00 & 3.06 & 1.09 & 0.755 \\
\hline $95 \% \mathrm{Cl}$ & & $0.89,10.49$ & $0.30,3.96$ & \\
\hline \multicolumn{5}{|l|}{$18: 3 n-3$} \\
\hline No. of cases & 47 & 3 & 0 & \\
\hline No. of controls & 16 & 17 & 17 & \\
\hline Blood fatty acids cut-off & $\leq 0.91$ & $0.91<$ to $\leq 1.60$ & $>1.60$ & \\
\hline OR & 1.00 & $0.04^{\star \star *}$ & 0.00 & $<0.001$ \\
\hline $95 \% \mathrm{Cl}$ & & $0.01,0.22$ & $0.00,0.00$ & \\
\hline \multicolumn{5}{|l|}{$20: 3 n-6$} \\
\hline No. of cases & 20 & 11 & 19 & \\
\hline No. of controls & 16 & 17 & 17 & \\
\hline Blood fatty acids cut-off & $\leq 1.38$ & $1.38<$ to $\leq 1.59$ & $>1.59$ & \\
\hline OR & 1.00 & 0.43 & $1 \cdot 20$ & 0.829 \\
\hline $95 \% \mathrm{Cl}$ & & $0.13,1.45$ & $0.40,3.65$ & \\
\hline \multicolumn{5}{|l|}{$20: 4 n-6$} \\
\hline No. of cases & 11 & 8 & 31 & \\
\hline No. of controls & 16 & 17 & 17 & \\
\hline Blood fatty acids cut-off & $\leq 12.50$ & $12.50<$ to $\leq 13.87$ & $>13 \cdot 87$ & \\
\hline OR & 1.00 & 0.55 & 2.98 & $<0.001$ \\
\hline $95 \% \mathrm{Cl}$ & & $0 \cdot 14,2 \cdot 11$ & $0.95,9.34$ & \\
\hline
\end{tabular}


Table 3. Continued

\begin{tabular}{|c|c|c|c|c|}
\hline & \multicolumn{3}{|c|}{ Tertile of erythrocyte fatty acid concentration (\%) } & \multirow[b]{2}{*}{$P$ trend $\ddagger$} \\
\hline & 1 & 2 & 3 & \\
\hline \multicolumn{5}{|l|}{$20: 5 n-3$} \\
\hline No. of cases & 44 & 5 & 1 & \\
\hline No. of controls & 16 & 17 & 17 & \\
\hline Blood fatty acids cut-off & $\leq 2.49$ & $2.49<$ to $\leq 3.60$ & $>3.60$ & \\
\hline OR & 1.00 & $0.05^{\star \star \star}$ & $0.02^{\star *}$ & $<0.001$ \\
\hline $95 \% \mathrm{Cl}$ & & $0.01,0.24$ & $0.00,0.19$ & \\
\hline \multicolumn{5}{|l|}{$22: 4 n-6$} \\
\hline No. of cases & 12 & 15 & 23 & \\
\hline No. of controls & 16 & 17 & 17 & \\
\hline Blood fatty acids cut-off & $\leq 1.84$ & $1.84<$ to $\leq 2.28$ & $>2 \cdot 28$ & \\
\hline OR & 1.00 & 1.64 & $2 \cdot 41$ & 0.134 \\
\hline $95 \% \mathrm{Cl}$ & & $0.49,5.45$ & $0.76,7.63$ & \\
\hline \multicolumn{5}{|l|}{$22: 5 n-3$} \\
\hline No. of cases & 14 & 28 & 8 & \\
\hline No. of controls & 16 & 17 & 17 & \\
\hline Blood fatty acids cut-off & $\leq 2.54$ & $2.54<$ to $\leq 3.13$ & $>3.13$ & \\
\hline OR & 1.00 & 0.83 & $0 \cdot 15^{\star}$ & 0.023 \\
\hline $95 \% \mathrm{Cl}$ & & $0.25,2.78$ & $0.03,0.68$ & \\
\hline \multicolumn{5}{|l|}{$22: 6 n-3$} \\
\hline No. of cases & 24 & 16 & 10 & \\
\hline No. of controls & 16 & 17 & 17 & \\
\hline Blood fatty acids cut-off & $\leq 7.72$ & $7.72<$ to $\leq 9.00$ & $>9.00$ & \\
\hline OR & 1.00 & 0.67 & 0.34 & 0.077 \\
\hline $95 \% \mathrm{Cl}$ & & $0 \cdot 21,2 \cdot 11$ & $0.10,1 \cdot 12$ & \\
\hline \multicolumn{5}{|l|}{ Omega-3 Index } \\
\hline No. of cases & 35 & 12 & 3 & \\
\hline No. of controls & 16 & 17 & 17 & \\
\hline Blood fatty acids cut-off & $\leq 10.43$ & $10 \cdot 43<$ to $\leq 12.98$ & $>12.98$ & \\
\hline OR & 1.00 & 0.42 & $0.08^{\star *}$ & 0.001 \\
\hline $95 \% \mathrm{Cl}$ & & $0.14,1.30$ & $0.02,0.38$ & \\
\hline \multicolumn{5}{|l|}{ Total trans-fatty acids } \\
\hline No. of cases & 1 & 1 & 48 & \\
\hline No. of controls & 17 & 16 & 16 & \\
\hline Blood fatty acids cut-off & $\leq 0.06$ & $0.06<$ to $\leq 0.45$ & $>0.45$ & \\
\hline OR & 1.00 & 0.50 & $72 \cdot 67^{\star \star \star}$ & $<0.001$ \\
\hline $95 \% \mathrm{Cl}$ & & $0 \cdot 02,12 \cdot 16$ & $6 \cdot 68,790 \cdot 74$ & \\
\hline \multicolumn{5}{|c|}{$\begin{array}{l}\text { Omega-3 Index, sum of EPA and DHA. } \\
{ }^{*} P<0.05,{ }^{\star *} P<0.01,{ }^{* \star *} P<0.001 \text { (logistic regression analysis). }\end{array}$} \\
\hline \multicolumn{5}{|c|}{$\begin{array}{l}\text { TOR and } 95 \% \mathrm{Cl} \text { were analysed by logistic regression. OR in cases and controls were adjusted for age, sex, } \\
\text { history of diabetes, family history of CHD, smoking status, hypertension status, and levels of glucose, total } \\
\text { cholesterol and HDL-cholesterol. }\end{array}$} \\
\hline ‡Estimates of $P$ values for a & ir trend wer & ased on linear scores $d$ & rived from the media & f tertiles of \\
\hline
\end{tabular}

acid profile significantly and substantially improved acute non-fatal MI case discrimination compared with traditional CHD risk factors, suggesting that the erythrocyte fatty acid profile is more powerful than the Framingham risk score for identifying patients with acute non-fatal MI.
The traditional Framingham risk score predicts CHD with an accuracy of $70-80 \%(9,17)$, but measurement of the tissue levels of fatty acids could serve as screening tool to assess MI risk and guide dietary interventions using an evidence-based approach.

Table 4. Correlation between fatty acid composition of erythrocytes and metabolic parameters determined by partial correlation analysis (Partial correlation coefficients adjusted for age and sex)

\begin{tabular}{lcccccrrr}
\hline & $\begin{array}{c}\text { hs-CRP } \\
(\mathrm{mg} / \mathrm{l})\end{array}$ & $\begin{array}{c}\text { Leptin } \\
(\mu \mathrm{g} / \mathrm{l})\end{array}$ & $\begin{array}{c}\text { Adiponectin } \\
(\mathrm{mg} / \mathrm{l})\end{array}$ & $\begin{array}{c}\text { Glucose } \\
(\mathrm{mg} / \mathrm{l})\end{array}$ & $\begin{array}{c}\text { TAG } \\
(\mathrm{mg} / \mathrm{l})\end{array}$ & $\begin{array}{r}\text { LDL-cholesterol } \\
(\mathrm{mg} / \mathrm{l})\end{array}$ & $\begin{array}{r}\text { HDL-cholesterol } \\
(\mathrm{mg} / \mathrm{l})\end{array}$ & $\begin{array}{c}\text { Total cholesterol } \\
(\mathrm{mg} / \mathrm{l})\end{array}$ \\
\hline trans-18: $1 n-9$ & $0.453^{\star \star *}$ & 0.161 & $-0.222^{*}$ & 0.112 & 0.077 & 0.030 & 0.134 & 0.042 \\
trans-18:2n-6 & 0.076 & 0.096 & -0.061 & 0.009 & $0.278^{\star \star}$ & -0.193 & -0.008 & -0.006 \\
$18: 2 n-6$ & 0.083 & -0.079 & 0.038 & -0.013 & $-0.273^{*}$ & $0.213^{*}$ & $0.245^{*}$ & -0.035 \\
$18: 3 n-3$ & $-0.275^{*}$ & -0.206 & 0.129 & $-0.238^{*}$ & -0.119 & -0.164 & -0.167 & -0.163 \\
$20: 5 n-3$ & $-0.270^{*}$ & -0.116 & 0.125 & $-0.223^{*}$ & -0.087 & -0.125 & -0.111 & $-0.219^{*}$ \\
Omega-3 Index & $-0.276^{*}$ & -0.171 & 0.081 & $-0.214^{*}$ & 0.002 & -0.066 & -0.202 & -0.142 \\
\hline
\end{tabular}

hs-CRP, high-sensitivity C-reactive protein; Omega-3 Index, sum of EPA and DHA in erythrocytes.

${ }^{\star} P<0.05,{ }^{\star \star} P<0.01,{ }^{* \star *} P<0.001$. 


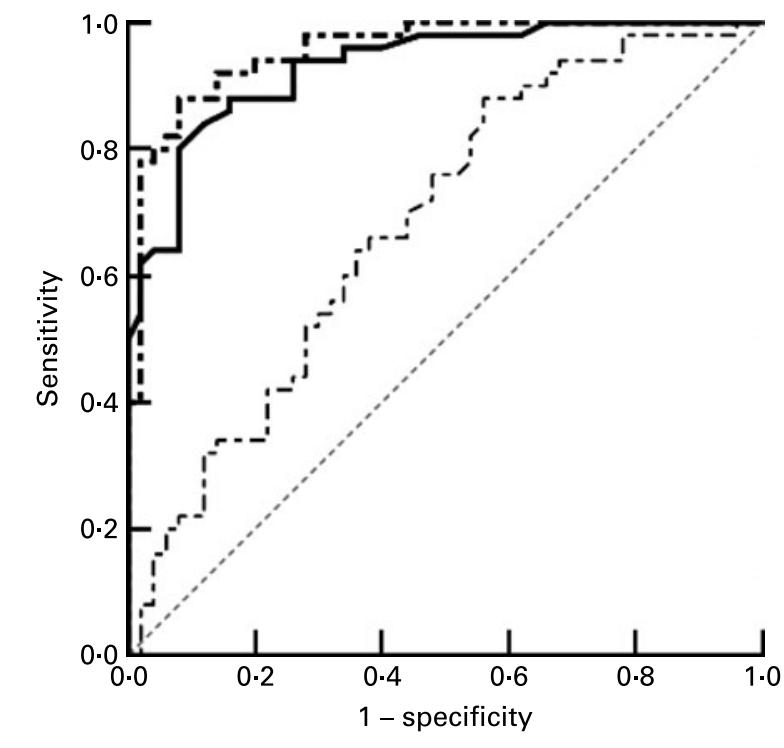

Fig. 1. The ability of the fatty acid profile of erythrocytes to discrimination between myocardial infarction cases and controls was assessed in the validation set using receiver operating characteristic curves. The fatty acids risk score (-- ) included levels of EPA, $\alpha$-linolenic acid, trans-oleic acid and arachidonic acid; the traditional risk score (-- ) included Framingham risk factors such as age, sex, smoking status, total cholesterol, HDL-cholesterol, and a history of diabetes and hypertension; a combined risk score included traditional plus fatty acids risk score factors (-). (-- -), Reference line.

Previous CHD studies have found inverse associations between $n-3$ fatty $\operatorname{acids}^{(6,18-21)}$ and trans-fatty acids $^{(12,22-24)}$. Of the four fatty acids included in the model, increasing levels of two (EPA and ALA) were inversely associated with the OR for MI case status, while a direct association between the levels of trans-oleic acid and arachidonic acid levels and the OR for MI was found. Most studies have suggested that $n-3$ fatty acids, particularly DHA, are more cardioprotective than $\mathrm{EPA}^{(16)}$, and because tissue phospholipid DHA proportions are considerably higher than EPA $(2 \cdot 1 v .0 .8 \%)$, the former may give a stronger signal and have lower variability. However, EPA reduced major coronary events by $19 \%$ in patients with a history of coronary artery disease in the Japan EPA Lipid Intervention Study (JELIS) when the plasma level of EPA was about $2 \cdot 6 \%^{(4)}$. EPA has many beneficial effects ${ }^{(14)}$, including hypolipidaemic and anti-platelet activities ${ }^{(25)}$, and plaque-stabilising properties ${ }^{(26)}$. In the present study, only EPA was associated with MI in Korean patients; the EPA levels of erythrocytes were $3.47 \%$ in controls and $1.68 \%$ in cases, similar to the values reported in a Japanese population and higher than those reported in an American study $(0.46 \% \text { in cases } v .0 .72 \% \text { in controls })^{(24)}$. Block et al. ${ }^{(24)}$ also reported DHA levels of $2.93 \%$ in cases and $3.53 \%$ in controls, which were lower than the Korean controls of $8.35 \%$ and cases of $7.89 \%$ in the present study.

EPA competes with arachidonic acid, the precursor of $\mathrm{PGE}_{2}$ and leucotriene $\mathrm{B}_{4}$, thereby producing pro-inflammatory and thrombotic effects ${ }^{(27)}$. Thus, a high intake of $n-6$ fatty acids is characterised by increases in blood viscosity, vasospasm and vasoconstriction, and $n-3$ fatty acids are associated with a decrease in blood viscosity and have anti-inflammatory, anti-thrombotic, anti-arrhythmic, hypolipidaemic and vasodilatory properties ${ }^{(16)}$. Arachidonic acid content in adipose tissue is associated with increased risk of $\mathrm{MI}^{(24,28)}$, but a meta-analysis of case-control and prospective cohort studies found that increased arachidonic acid content in phospholipids or TAG was not significantly associated with $\mathrm{CHD}^{(13)}$. However, Block et al. ${ }^{(24)}$ reported that there was a significant difference in arachidonic acid content between patients with acute coronary syndrome status and controls, and that arachidonic acid had a U-shaped relationship with the risk of acute coronary syndrome status. In the present study, the relationship of arachidonic acid to MI was also U-shaped; compared with the first quartile of arachidonic acid, the OR for case status in the second and third quartiles were 0.55 (95\% CI $0.14,2.11$ ) and 2.98 (95\% CI 0.95, 9.34), respectively. Fatty acids are measured as proportions; thus higher arachidonic and lower EPA levels may be associated with an increased risk of acute non-fatal MI.

Trans-fatty acids are associated with the risk of $\mathrm{CHD}^{(22)}$. Clifton et al. ${ }^{(12)}$ and Pedersen et al. ${ }^{(28)}$ found a positive association between MI and adipose tissue levels of transoleic acid. Block et al. ${ }^{(24)}$ measured fatty acids in erythrocytes and reported that high levels of trans-oleic acid were associated with acute coronary syndrome, whereas levels of trans-linoleic acid did not show a significant association with acute coronary syndrome. In the present study, we consistently found that the trans-oleic acid content of erythrocytes was associated with an increased risk of acute non-fatal MI. Although margarine, beef and dairy consumption have been linked to CHD, it has been difficult to link trans-fatty acids in erythrocytes from these sources to MI. Although the usual case-control design is prone to bias, the use of fatty acid biomarkers may be more reliable than dietary measures, and MI does not alter the tissue fatty acid composition ${ }^{(29)}$. Furthermore, the acute interventions commonly used to treat MI patients upon admission are not expected to alter the fatty acid composition of erythrocytes; however, we could not evaluate this assumption in the present study because blood samples were drawn upon admission.

The hypotriacylglycerolaemic effect of $n-3$ fatty acids is well established, and has been ascribed to the reduced hepatic synthesis of VLDL and increased catabolism of VLDL ${ }^{(30)}$. A meta-analysis indicated that among all classes of fatty acids, trans-fatty acids have the strongest effect on raising serum LDL-cholesterol levels ${ }^{(31)}$. However, we did not find a significant association between erythrocyte fatty acids and lipoprotein levels with the exception of the level of EPA, which was negatively associated with the levels of total cholesterol and trans-linoleic acid and positively associated with the concentration of TAG. Small sample sizes, inadequate biomarkers and uncontrolled confounding factors may explain the discrepancies between these studies.

In conclusion, the fatty acid profile of erythrocytes can discriminate better between acute non-fatal MI cases and controls than the Framingham risk score. Increased levels of $n-3$ fatty acids and decreased levels of trans-fatty acids and n-6 fatty acids are associated with decreased odds of MI. These findings suggest that the fatty acid profile of erythrocytes may contain metabolomic information, and thus be of prognostic value in the diagnosis of non-fatal MI. Although prospective validation and a larger study are required, fatty acid profiles may have clinical utility for non-fatal MI risk assessment. 


\section{Acknowledgements}

The present study was supported by a Korean Research Foundation grant funded by the Korean Government (MOEHD, Basic Research Promotion Fund; KRF-2007-331-C00279).

Y. P. is the principal investigator for this project and wrote the manuscript; J. Lim conducted the laboratory and statistical analysis; J. Lee recruited MI patients and collected medical information, and advised on the clinical part of this paper; S. K. recruited control patients and collected medical information, and advised on the clinical part of this paper.

The authors state that there are no conflicts of interest.

\section{References}

1. Wang C, Harris WS, Chung M, et al. (2006) n-3 Fatty acids from fish or fish-oil supplements, but not $\alpha$-linolenic acid, benefit cardiovascular disease outcomes in primary- and secondary-prevention studies: a systematic review. Am J Clin Nutr 84, $5-17$.

2. Burr ML, Fehily AM, Gilbert JF, et al. (1989) Effects of changes in fat, fish, and fibre intakes on death and myocardial reinfarction: diet and reinfarction trial (DART). Lancet 334, 757-761.

3. Marchioli R, Barzi F, Bomba E, et al. (2002) Early protection against sudden death by $n-3$ polyunsaturated fatty acids after myocardial infarction: time-course analysis of the results of the Gruppo Italiano per lo Studio della Sopravvivenza nell'Infarto Miocardico (GISSI)-Prevenzione. Circulation 105, 1897-1903.

4. Yokoyama M, Origasa H, Matsuzaki M, et al. (2007) Effects of eicosapentaenoic acid on major coronary events in hypercholesterolaemic patients (JELIS): a randomized open-label, blinded endpoint analysis. Lancet 369, 1090-1098.

5. Hu FB, Bronner L, Willett WC, et al. (2002) Fish and omega-3 fatty acid intake and risk of coronary heart disease in women. JAMA 287, 1815-1821.

6. Sun Q, Ma J, Campos H, et al. (2008) Blood concentrations of individual long-chain $n-3$ fatty acids and risk of non-fatal myocardial infarction. Am J Clin Nutr 88, 216-223.

7. Ascherio A, Rimm EB, Stampfer MJ, et al. (1995) Dietary intake of marine $n-3$ fatty acids, fish intake, and the risk of coronary disease among men. $N$ Engl J Med 332, 977-982.

8. Morris MC, Manson JE, Rosner B, et al. (1995) Fish consumption and cardiovascular disease in the Physicians' Health Study: a prospective study. Am J Epidemiol 142, 166-175.

9. Chambless LE, Folsom AR, Sharrett AR, et al. (2003) Coronary heart disease risk prediction in the atherosclerosis risk in communities (ARIC) study. J Clin Epidemiol 56, 880-890.

10. Wilson PW, D'Agostino RB, Levy D, et al. (1998) Prediction of coronary heart disease using risk factor categories. Circulation 97, 1837-1847.

11. Harris WS \& Von Schacky C (2004) The Omega-3 Index: a new risk factor for death from coronary heart disease? Prev Med 39, 212-220.

12. Clifton PM, Keogh JB \& Noakes M (2004) Trans fatty acids in adipose tissue and the food supply are associated with myocardial infarction. $J$ Nutr 134, 874-879.
13. Harris WS, Poston WC \& Haddock CK (2007) Tissue $n$-3 and $n-6$ fatty acids and risk for coronary heart disease events. Atherosclerosis 193, 1-10.

14. Harris WS, Park Y \& Isley WL (2003) Cardiovascular disease and long-chain omega-3 fatty acids. Curr Opin Lipidol 14, $9-14$.

15. Mozaffarian D, Pischon T, Hankinson SE, et al. (2004) Dietary intake of trans fatty acids and systemic inflammation in women. Am J Clin Nutr 79, 606-612.

16. Mori TA \& Woodman RJ (2006) The independent effects of eicosapentaenoic acid and docosahexaenoic acid on cardiovascular risk factors in humans. Curr Opin Clin Nutr Metab Care 9, 95-104.

17. Wilson PW, D'Agostino RB, Levy D, et al. (1998) Prediction of coronary heart disease using risk factor categories. Circulation 97, 1837-1847.

18. Dewailly E, Blanchet C, Gingras S, et al. (2001) Relations between $n-3$ fatty acid status and cardiovascular disease risk factors among Quebecers. Am J Clin Nutr 74, 603-611.

19. Block RC, Harris WS, Reid KJ, et al. (2008) EPA and DHA in blood cell membranes from acute coronary syndrome patients and controls. Atherosclerosis 197, 821-828.

20. Harris WS, Poston WC \& Haddock CK (2007) Tissue $n-3$ and $n-6$ fatty acids and risk for coronary heart disease events. Atherosclerosis 193, 1-10.

21. Albert CM, Campos H, Stampfer MJ, et al. (2002) Blood levels of long-chain $n-3$ fatty acids and the risk of sudden death. $N$ Engl $J$ Med 346, 1113-1118.

22. Mozaffarian D, Katan MB, Ascherio A, et al. (2006) Trans fatty acids and cardiovascular disease. $N$ Engl $J$ Med 354, $1601-1613$.

23. Sun Q, Ma Jing, Campos H, et al. (2007) A prospective study of trans fatty acids in erythrocytes and risk of coronary heart disease. Circulation 115, 1858-1865.

24. Block RC, Harris WS, Reid KJ, et al. (2008) Omega-6 and trans fatty acids in blood cell membranes: a risk factor for acute coronary syndromes? Am Heart J 156, 1117-1123.

25. Park Y \& Harris WS (2002) EPA, but not DHA, decreases mean platelet volume in normal subjects. Lipids 37, 941-946.

26. Thies F, Garry JM, Yaqoob P, et al. (2003) Association of $n-3$ polyunsaturated fatty acids with stability of atherosclerotic plaques: a randomized controlled trial. Lancet 361, 477-485.

27. Wada M, DeLong CJ, Hong YH, et al. (2007) Enzymes and receptors of prostaglandin pathways with arachidonic acidderived versus eicosapentaenoic acid-derived substrates and products. J Biol Chem 282, 22254-22266.

28. Pedersen JI, Ringstad J, Almendingen K, et al. (2000) Adipose tissue fatty acids and risk of myocardial infarction- a casecontrol study. Eur J Clin Nutr 54, 618-625.

29. Kark JD, Manor O, Goldman S, et al. (1995) Stability of red blood cell membrane fatty acid composition after acute myocardial infarction. J Clin Epidemiol 48, 889-895.

30. De Caterina R, Madonna R, Bertolotto A, et al. (2007) n-3 Fatty acids in the treatment of diabetic patients: biological rationale and clinical data. Diabetes Care 30, 1012-1026.

31. Mensink RP, Zock PL, Kester AD, et al. (2003) Effects of dietary fatty acids and carbohydrates on the ratio of serum total to HDL cholesterol and on serum lipids and apolipoproteins: a meta-analysis of 60 controlled trials. Am J Clin Nutr 77, $1146-1155$. 